\title{
A Mediação Sanitária como alternativa viável à judicialização das políticas de saúde no Brasil
}

\author{
The Sanitary Mediation as a viable alternative to the judicialization \\ of health policies in Brazil
}

Maria Célia Delduque', Eduardo Vazquez de Castro²

\begin{abstract}
RESUMO A solução de controvérsias na saúde vem se dando pelo Poder Judiciário, gerando o fenômeno da judicialização. Essa forma de dirimir conflitos não atende ao SUS nem ao próprio órgão julgador. Este artigo empreende uma discussão sobre o instituto da Mediação, para contemplá-la como uma forma de exercício social de acesso à justiça. A Mediação é pouco utilizada no País. É ferramenta para a solução de controvérsias, a fim de evitar a necessidade de mobilização do Poder Judiciário. Trata-se de um instituto célere, de baixo custo e que mantém as garantias de acessibilidade à justiça como direito social. A Mediação pode amenizar as controvérsias que geram a judicialização.
\end{abstract}

PALAVRAS-CHAVE Decisões judiciais; Saúde; Negociação.

ABSTRACT The settlement of controversies in health has been going by the Judiciary, generating the Judicialization phenomenon. This way of settling conflicts does not meet the SUS neither the own judging body. This article undertakes a discussion about the Mediation Institute, to contemplate it as a form of fiscal year of access to justice. Mediation is not widely used in the country. It is a tool for the resolution of disputes settlement, in order to avoid the necessity of mobilization of the Judiciary. This is a quick institute, low cost, and which maintains the guarantees of accessibility to justice as a social right. Mediation can alleviate the controversies that generate legalization.

KEYWORDS Judicial decisions; Health; Negociation. 


\section{Introdução}

A famosa obra 'O acesso à justiça', de Cappelletti e Garth (1972), conta-nos que o acesso à justiça teve seu primeiro conceito forjado nos Estados liberais burgueses, onde a solução dos litígios e o acesso à justiça eram basicamente compreendidos como o direito do indivíduo de propor ou contestar uma ação, portanto, concentrado exclusivamente na justiça, exercida nos tribunais judiciais. Uma prática forense.

Com o aparecimento do Welfare State e a conquista dos direitos sociais, o aparecimento do sujeito empregado, consumidor, inquilino e cidadão fez com que o acesso à justiça passasse a ser uma preocupação do Estado garantidor dos direitos sociais. O acesso efetivo à justiça passou a ser considerado como um requisito básico - um direito humano fundamental - no sistema legal da modernidade, que pretendia garantir e não somente proclamar esse direito básico de todos (CAPPELLETTI; GARTH, 1972).

$\mathrm{O}$ acesso à justiça, para os autores, pode ser explicado por movimentos ou ondas. Tais ondas, embora sucessivas, convivem harmoniosamente, valendo-se umas das outras para a completa fruição do direito universal à justiça para todos. Assim, para os autores, as três ondas que representam os principais movimentos processualísticos para o pleno acesso de indivíduos e grupos à justiça não são processos que deixaram no passado suas práticas, para serem sucedidas por soluções mais novas de ampliação e garantismo de acesso a um sistema de justiça, mas movimentos que se ampliaram para abarcar um número maior de possibilidades de justiça, para alcançar todos os cidadãos.

Conforme já mencionado, são três as ondas de acesso à justiça. A primeira onda, ou a primeira solução de garantia de acesso, é o assessoramento legal, ou seja, a ajuda legal aos mais pobres; a segunda onda se caracteriza pelas reformas, cujo objeto é dar representação legal aos interesses difusos; e a mais recente, a terceira onda, é a que se propõe ao enfoque do acesso à justiça de uma forma mais articulada e completa: a Mediação, objeto deste artigo.

\section{Objetivo}

O texto discute a resolução de conflitos e o acesso à justiça por meio da Mediação, ferramenta que vem sendo utilizada no Brasil de forma acanhada, mas que tem demonstrado ser um potente instrumento de solução para controvérsias de muitas ordens. Essa forma alternativa de resolução de conflitos pode ser utilizada no âmbito do Sistema Único de Saúde (SUS), a fim de que as controvérsias que ensejam a conhecida 'judicialização' possam ser dirimidas em fóruns e instâncias que não o Poder Judiciário, sem perder de vista o Direito de Acesso à Justiça das partes, consagrado na Constituição de 1988, em seu art. $5^{\circ}$, inciso XXXV (BRASIL, 2012).

\section{Discussão}

$\mathrm{O}$ acesso a bens e serviços de saúde pela via judicial, no Brasil, vem evidenciando que o exercício do direito à saúde, pelos cidadãos, positivado em nosso ordenamento jurídico pela Carta Magna de 1988 (BRASIL, 2012), traz à tona a desordem de nossos sistemas político e jurídico com relação à garantia de direitos sociais.

Ao garantir um determinado bem ou serviço de saúde em juízo, como parte integrante do direito à saúde, o Poder Judiciário vem sendo acusado de exorbitar de suas funções de aplicar a lei ao caso concreto e interferir, reflexamente, nas políticas públicas que se destinam a garantir esse direito sob a perspectiva coletiva, prejudicando, assim, a equidade em saúde (CHIEFFI; BARATA, 2009).

$O$ conflito entre as necessidades individuais e coletivas que permeiam a garantia de um direito complexo, como o direito à 
saúde, vem mostrando que os sistemas político, jurídico e médico-sanitário chegaram ao esgotamento e que o Poder Judiciário não responde mais, com a eficácia esperada, à pacificação dessas controvérsias.

E é sobre esse conflito, que se convencionou chamar de 'judicialização das políticas de saúde', que este trabalho se debruça, objetivando construir caminhos de entendimento e enfrentamento do problema e apresentar uma alternativa viável ao acesso à justiça, para pacificar os conflitos na saúde, senão por intermédio dos tribunais.

Cappelletti e Garth (1972) e a figura das ondas da garantia do acesso à justiça reforçam que a assistência judiciária aos mais carentes foi a primeira onda dessa garantia. Segundo os autores, em verdade,

os primeiros esforços importantes para incrementar o acesso à justiça nos países ocidentais concentram-se, mais adequadamente, em proporcionar serviços jurídicos aos pobres. (CAPPELLETTI; GARTH, 1972, P. 24).

Essa forma de propiciar o acesso à justiça desenvolveu-se em muitos países. No Brasil, a assistência judiciária gratuita é prestada por inúmeras entidades, mas, especialmente, pela Defensoria Pública.

Único país do mundo a dar tratamento constitucional para a garantia do acesso das pessoas pobres à justiça, o Brasil ainda padece de organização, de forma definitiva e concreta, da Defensoria Pública, em alguns estados brasileiros, além de manter um crônico déficit de, aproximadamente, 10.578 defensores públicos em todo o País, o que acarreta, em consequência, um impeditivo acesso à justiça daqueles que dependem da assistência judiciária gratuita prestada pelo Estado (IPEA, 2013).

A segunda onda é a representação dos direitos difusos. Os chamados direitos difusos estão dentro da ideia de novos direitos, que, aliás, não são tão novos assim; a maioria deles nasceu na Revolução Francesa, e outros tantos se incorporaram no ordenamento jurídico pátrio, bem antes de 1988. Caracterizam-se pela indefinição da titularidade e pela indivisibilidade do direito perseguido.

$O$ fato é que os conflitos envolvendo interesses difusos têm chegado ao Judiciário e esbarrado em julgadores que não contam com uma tradição legal, porque o direito difuso é um direito novo. Tampouco contam com farta bibliografia, pois ainda há pouca produção intelectual sobre o tema, e, muito menos, com precedentes de decisões dos tribunais superiores que representem um pensamento jurídico novo, fazendo com que as decisões aconteçam em uma seara absolutamente recente e não consensual.

Surgem as class action, cuja decisão teria efeito sobre todos os indivíduos afetados, mesmo aqueles que não tivessem participado do processo judicial. Na legislação brasileira, é a Ação Civil Pública o instrumento processual cabível para ajuizar ações junto ao Poder Judiciário para demandar por direitos difusos. Mas o Ministério Público tem outros instrumentos extrajudiciais para a proteção dos direitos difusos, como o Termo de Ajustamento de Conduta. Igualmente, as agências reguladoras têm a função de regular um mercado em que sujeitos indefinidos de direito podem sofrer danos em seus direitos difusos e coletivos.

A saúde pública é um direito difuso, no entanto, não se tem notícia de Ações Civis Públicas ou mesmo ações coletivas que cheguem aos tribunais para tratar de modo generalizado de temas que afetem a saúde das pessoas, indistintamente.

A terceira e última onda de acesso à representação legal - e a mais ampla concepção de acesso à justiça - é um novo enfoque que deve ser levado a efeito fora do circuito jurisdicional. Isso porque, assim como surgiram direitos materiais de terceira geração, como defende Bobbio (2004), também surgiram direitos como a participação na decisão do conflito e no acesso à justiça, que se constituem em direitos processuais de terceira geração (CAPPELLETTI; GARTH, 1996). Ocorre 
que, na decisão judicial, as partes não participam da decisão do conflito, mas apenas se submetem, inertes, à decisão do terceiro, o juiz da causa.

Por vezes, a jurisdição não é capaz de dar solução adequada a certos tipos de conflito por desconhecer o campo do conhecimento do tema posto a seu julgamento e por, muitas vezes, exercer a função jurisdicional de aplicação da lei ao caso concreto, afirmando-se na função substitutiva do sistema político e "destecnificando" a aplicação da lei; por consequência, levando à judicialização da vida administrativa e econômica (FARIA, 2004, P. 103).

Assim acontece com a saúde. Por desconhecer as políticas públicas formadoras do SUS, a jurisdição não tem solucionado o acesso a bens e serviços de saúde. Ao contrário, tem criado distorções no sistema e dado ao conceito de acesso à justiça um sentido reverso, em que uns poucos privilegiados, que podem ter acesso aos tribunais, obtêm uma sentença.

Vários estudiosos do tema têm-se colocado de modo contundente sobre a situação das reiteradas decisões judiciais no âmbito da saúde, que infringem ou distorcem princípios do SUS, sobretudo o da equidade. (CHIEFFI; BARATA, 2009; BORGES; UGÁ, 2010; SARTÓRIO; BORDIN, 2010; MACEDO, 2011).

Assim, tem-se que o exercício de um direito fundamental pelos cidadãos pode acarretar sérios prejuízos políticos, com a exacerbação da atuação do Poder Judiciário para além de seus limites funcionais, a gerar impactos significativos na implementação e execução da política pública de saúde.

A judicialização da política é uma expressão equivalente à 'politização da justiça', e pode ser traduzida pela expansão do Poder Judiciário no processo decisório. Werneck Vianna (1999) utiliza o termo para descrever as transformações trazidas pela Constituição Federal de 1988, no Brasil, que alargam as possibilidades de ações junto ao Poder Judiciário, para que este defenda os direitos, individuais e sociais, resguardados pela Constituição. Para Maciel e Koerner (2002), a expressão judicialização da política recebe um sentido de processo social e político quando é usada para se referir à "expansão do âmbito qualitativo de atuação do sistema judicial, do caráter dos procedimentos de que dispõem e, ainda, aumento do número de processos no Tribunal" (MACIEL; KOERNER, 2002, P. 115).

Dados da Consultoria Jurídica do Ministério da Saúde (ADVOCACIA GERAL DA UNIÃO, 2012) apontam que há um crescente número de ações judiciais em matéria de saúde, nos últimos anos, sendo que, apenas em 2011, o total de novas ações atingiu o número de 12.811, apenas em nível federal (ADVOCACIA GERAL DA UNIÃO, 2012). Isso equivale a um aumento de $15 \%$ se comparado ao número de processos iniciados no ano anterior.

Para termos uma ideia do que representa esse elevado número de ações judiciais, os gastos, em 2012, somente em medicamentos, sem levar em conta as despesas com a efetiva aquisição dos mesmos, o transporte e a efetiva entrega, seguro e quando não a importação, chegaram a R\$243.954.000,00 (ADVOCACIA GERAL DA UNIÃO, 2012).

São aquisições não programadas, não pertencentes ao normal planejamento do setor da saúde, que podem resultar em gastos extraordinários com processos administrativos de dispensas de licitação. Tais situações acabam por concorrer com o normal abastecimento do SUS, acarretando uma irregular divisão de esforços materiais, humanos e orçamentários para atender à judicialização.

O mesmo se passa no Poder Judiciário. $\mathrm{O}$ novo afluxo de processos na área de direitos sociais, entre eles, os da saúde, fez com que a jurisdição tivesse um aporte maior no já sobrecarregado sistema judicial. Segundo Serbena et al. (2013), em 2010, ingressaram no cômputo geral 24,2 milhões de novos processos na Justiça, somando-se aos 59, 2 milhões de processos pendentes de sentença. Ademais, não há pesquisas específicas sobre o custo unitário de um processo judicial em 
matéria de saúde, mas o Instituto de Pesquisa Econômica Aplicada (Ipea), em um trabalho pioneiro sobre o custo de um processo judicial de execução fiscal, pôde dar uma ideia do custo individual de uma ação judicial para o Estado. Segundo o estudo (IPEA, 2013), o valor individual de um processo de execução fiscal na Justiça Federal, em primeiro grau, é de $\mathrm{R} \$$ 7.063,74, o que poderia ser usado como parâmetro para o custo de um processo judicial na área da saúde, no âmbito do Poder Judiciário.

Como se vê, esse fenômeno, que se convencionou chamar de judicialização da saúde, não é razoável para o sistema sanitário nem tampouco para o sistema da justiça. Além disso, o controle judicial das políticas públicas prejudica o pleno exercício da cidadania, pois torna o indivíduo dependente do Estado, e o Poder Judiciário seu fornecedor de serviços.

No Brasil, os litígios em matéria de saúde que possuem mais evidência são aqueles em que o acesso é o objeto material da demanda. De um lado está o cidadão enfermo, demandando ações ou insumos de saúde contra o Estado, provedor de serviços públicos de saúde, que, por razões de ausência do serviço ou da não previsibilidade deste nas políticas públicas, deixa de oferecê-los. Trata-se de um 'enfrentamento social' que ganhou proporções epidêmicas. Os mecanismos clássicos de resolução dos conflitos acabaram por produzir externalidades negativas para o SUS, já debilitado por razões diversas.

Mas, retomando as ondas de Cappelletti e Garth (1972), pergunta-se: e o que a terceira onda tem a ver com a judicialização da saúde e o movimento universal de acesso à justiça?

Os autores reconhecem que a terceira onda deve estar fora do circuito jurisdicional e que uma das diversas formas para a concretização da justiça, pela autocomposição, é a Mediação.

O conceito de Mediação, segundo a Diretiva 2008/52, da Comunidade Europeia, é:

um procedimento estruturado, seja qual for seu nome ou denominação, em que duas ou mais partes em litígio tentam voluntariamente alcançar por si mesmas um acordo sobre a resolução de um litígio com a ajuda de um mediador. (UNIÃO EUROPEIA, 2008).

Para Vazquez de Castro (2010), essa maneira de resolver conflitos pela autocomposição - em que as partes contam com um terceiro neutro, mas que pode desempenhar um papel ativo no processo de adoção de acordos no sentido de superar o litígio - é a Mediação.

A Mediação, como método pacífico de gestão de conflitos, pretende evitar a abertura de processos judiciais de caráter contencioso e pôr fim àqueles iniciados ou reduzir o seu alcance.

Cebola (2013, P. 19) dispõe que:

O direito de acesso ao Direito, pilar fundamental do Estado de Direito, vem sofrendo profundas transformações. Deixou de ser um direito de acesso ao Direito através do direito de acesso aos tribunais para passar a ser um direito de acesso ao Direito, de preferência sem contato ou sem passagem pelos tribunais.

Reconhecido o direito de acesso à justiça como um direito a recorrer a todos os meios legítimos, legais e válidos para solucionar conflitos, sejam judiciais ou extrajudiciais, resta analisar se tal orientação contraria a Carta de 1988.

Ante à previsão do artigo $5^{\circ}$, inciso XXXV: "a lei não excluirá da apreciação do Poder Judiciário lesão ou ameaça a direito" (BRASIL, 2012, P. 17), que implica o poder de acudir-se de um tribunal para a resolução de um conflito jurídico. É oportuno questionar se, nesse contexto, há admissibilidade dos meios extrajudiciais.

A questão ganha maior importância frente à Resolução 127 do Conselho Nacional de Justiça (CNJ), conhecida como Política Judiciária Nacional, que, entre outras medidas, prevê o movimento pela conciliação. 
Desde 2006, a Secretaria de Reforma do Judiciário (SRJ), do Ministério da Justiça, em ação conjunta com o CNJ, vem capacitando mediadores por meio da Escola Nacional de Mediação e Conciliação (Enam), com o intuito de realizar uma lenta transformação da sociedade brasileira, no sentido de criar a cultura do consenso e da cooperação na composição das disputas, aceitando-se um polissêmico conceito de justiça. Os sucessivos cursos de mediadores são voltados para operadores do direito, membros da academia e da sociedade civil.

Assim é que a Carta Política, de 1988, consagra a jurisdição como monopólio do Estado, mas não impede outras formas de solução de conflitos.

O fato é que os Modelos Alternativos de Resolução de Conflitos representam a adesão à cultura da pacificação, em oposição à cultura hoje existente em torno da necessidade de uma decisão judicial para que a controvérsia possa ser resolvida. Isso porque a solução pacífica é sempre preferível, inclusive economicamente, deixando, por derradeiro, a busca do aparato Judicial. Há uma atmosfera favorável para tais modelos, entendidos como instância legitimada para a solução de conflitos sociais pelo próprio meio social, gerando maior conscientização política e participação popular. Esse entendimento foi muito bem incorporado no Decreto 8.243/2014, que estabeleceu a Política Nacional de Participação Social, em que são previstas as Mesas de Diálogo. Delduque, Alves e Dallari (2014) confirmam essa assertiva quando destacam:

a Mesa de Diálogo representa um esforço em todos os níveis para gerar um efetivo acesso à justiça, representando um novo mecanismo que pode ser considerado um esforço de Mediação. (DELDUQUE; ALVES; DALLARI, 2014, P. 2).

Também, Boaventura Santos (2005) costuma afirmar que:

não me parece tampouco que esses mecanismos de resolução dos litígios à margem do controle do Estado sejam intrinsicamente negativos ou atentatórios da democracia. Podem, pelo contrário, ser agentes de democratização da sociedade. (SANTOS, 2005, P. 157).

Deste modo, têm-se três formas de resolver os conflitos: a) as resoluções estatais - ou heterocomposição dos conflitos, como são hoje conhecidas as decisões judiciais; b) as resoluções estatais negociadas com as partes - ou autocomposição -, realizadas no âmbito jurisdicional, prévia ao início do processo ou no âmbito de órgãos auxiliares da justiça, como o Ministério Público, a Defensoria Pública e a Advocacia Geral da União; e c) a resolução dos conflitos - ou autocomposição dos conflitos -, em âmbitos extrajudiciais, privados ou não.

O SUS tem recebido preciosa ajuda dessa forma de resolução de conflitos, com dignas iniciativas de juízes, membros do Ministério Público, defensores públicos e advogados da União e procuradores, que, instituindo grupos de Mediação, realizam um trabalho a partir da demanda individual, para mediar o conflito entre o paciente/autor e o gestor da saúde, com o intuito de evitar a ação judicial.

Dois exemplos exitosos da utilização da Mediação na área da saúde, no Brasil, ocorrem no Ministério Público de Minas Gerais e na Defensoria Pública do Distrito Federal.

Em Brasília, a Câmara Permanente Distrital de Mediação em Saúde, da Defensoria Pública do DF, tem por objetivo mediar conflitos entre os pacientes usuários do SUS-DF e os gestores da rede pública de saúde da Capital.

No Estado de Minas Gerais, o Centro de Apoio Operacional das Promotorias de Justiça de Defesa da Saúde percorre regiões do estado realizando reuniões de conciliação entre usuários e gestores, além de tratar de temas específicos, como saúde prisional, incorporação tecnológica e outros.

Mas, embora rendendo frutos extraordinários, a Mediação desses conflitos mantém-se fora do sistema da saúde. No entanto, os conflitos são do sistema e devem ser solucionados pelo próprio sistema. 
Assim, é preciso que se descreva o que vem a ser a Mediação Sanitária.

A Mediação Sanitária é um modelo alternativo de resolução de conflitos na área da saúde. As relações em saúde transcendem a ótica bilateral do médico com o paciente, para envolver muitos outros atores presentes em um sistema de saúde, advindo, daí, conflitos de toda a ordem, internos e externos ao sistema, criando condições para a judicialização. Conflitos internos (como os assistenciais, organizativos e conflitos entre profissionais) geram desgastes e judicialização, como também fazem os conflitos gerados fora do sistema, mas com reflexos diretos dentro dele, assim como os conflitos sociais e conflitos legais igualmente geram a judicialização.

\section{Conclusão}

Assim, para além da resolução dos conflitos pela Mediação Sanitária, é possível, também, antever os conflitos, precavendo-se de seus efeitos por intermédio da construção e permanente atenção ao mapa dos conflitos no âmbito do SUS, fazendo com que o sistema possa operar antecipando-se aos conflitos futuros, solucionando-os.

\section{Referências}

\section{ADVOCACIA GERAL DA UNIÃO. Intervenção Judicial na saúde pública: panorama no âmbito da Justiça Federal e Apontamentos na seara das Justiças Estaduais. Disponível em: < http://www.portalsaude. saude.gov.br/portalsaude/.../Panorama\%20da\%20judi- cializaçao> Acesso em: 16 mar. 2014.}

BOBBIO, N. A era dos Direitos. Rio de Janeiro: Campus, 2004.

BORGES, D. C. L.; UGÁ, M. A. R. Conflitos e impasses da judicialização na obtenção de medicamentos: as decisões de $1^{\mathrm{a}}$ instância nas ações individuais contra $o$ Estado do Rio de Janeiro, Brasil em 2005. Cadernos de Saúde Pública, Rio de Janeiro, v. 26, n. 1, p. 59-69, 2010.
Para tanto, é preciso incutir uma nova prática, uma nova cultura no âmbito do SUS. Uma vigilância permanente dos conflitos sanitários, que pode ocorrer de muitos modos. A construção de núcleos de Mediação Sanitária, no âmbito das Secretarias de Saúde, em todos os níveis, para operar a Mediação interna ao sistema e externa com seus usuários, há de ser um novo paradigma a substituir a litigância e a judicialização.

Aos órgãos do Poder Judiciário, que têm se esforçado enormemente para diminuir a litigância na saúde, que implementem, igualmente, a conciliação prévia, como já previsto no Código de Processo Civil.

É preciso, ainda, questionar a formação do bacharel em direito que se submete ao concurso de juiz; o membro do Ministério Público ou o Defensor Público sobre o seu modo tradicional, litigioso e adversarial de operar o direito.

É necessária uma nova postura da sociedade brasileira para uma nova necessidade social, especialmente na saúde, de resolver conflitos e afastar, de vez, esse abismal modelo tradicional de julgar por meio dos clássicos tribunais e juízes. É preciso adotar a Mediação nos litígios da saúde.

BRASIL. Constituição (1988). Constituição da República Federativa do Brasil. Brasília: Senado Federal, 2012.

CAPPELLETTI, M.; GARTH, B. G. El acceso a la justicia: la tendencia en el movimiento mundial para hacer efectivos los derechos. Madrid: Fondo de Cultura Economica, 1996.

CEBOLA, C. M. La mediación. Madrid: Marcial Pons, 2013. $273 \mathrm{p}$.

CHIEFFI, A. L.; BARATA, R. B. Judicialização da assistência farmacêutica e equidade. Cadernos de Saúde Pública, Rio de Janeiro, v. 25, n. 8, p. 1839-1849, 2009. 
DELDUQUE, M. C.; ALVES, S. M.; DALLARI, S. G. Decreto que institui a Política Nacional de Participação Social: impactos na saúde. Cadernos de Saúde Pública, Rio de Janeiro, v. 30, n. 9, p. 1-3, 2014.

FARIA, J. E. O sistema brasileiro de Justiça: experiência recente e futuros desafios. Revista de Estudos Avançados, São Paulo, v. 51, n. 18, p. 103-125, 2004.

\section{INSTITUTO DE PESQUISA ECONÔMICA}

APLICADA (IPEA). Mapa da Defensoria 2013.

Disponível em: <http://www.ipea.gov.br/sites/mapadefensoria/desafios>. Acesso em: 11 mar. 2014.

MACEDO, E. I. Análise técnica para a tomada de decisão do fornecimento de medicamento pela via judicial. Revista de Saúde Pública, Rio de Janeiro, v. 45, n. 4, p. 703-713, 2011.

MACIEL, D.; KOERNER, A. Sentidos da judicialização da política: duas análises. Revista Lua Nova, São Paulo, n. 57 , p.113-133, 2002.

SANTOS, B. S. Pela mão de Alice: o social e o político na pós-modernidade. São Paulo: Cortez, 2005.

\section{SARTÓRIO, M. J.; BORDIN, R. Política de}

Medicamentos Excepcionais no Espírito Santos: a questão da judicialização da demanda. Saúde em Debate, Rio de Janeiro, v. 34, n. 85, p. 288-298, 2010.
SERBENA, C. A. et al. Justiça em Números: uma análise comparativa entre os sistemas judiciais brasileiro e de países europeus. Revista Democracia Digital e Governo Eletrônico, Florianópolis, n. 8, p. 73-92, 2013.

\section{UNIÃO EUROPEIA. Directiva 2008/52/CE del}

Parlamento Europeo y del Consejo, de 21 de mayo de 2008, sobre ciertos aspectos de la mediación en asuntos civiles y mercantiles. 2008. Disponível em: <http://eurlex.europa.eu/LexUriServ/LexUriServ.do?uri=CELEX: 3200810052:es:NOT>. Acesso em: 11 mar. 2014.

\section{VAZQUES DE CASTRO, E. La mediación en materia} de consumo: características y elementos de debate. In: VILLALUENGA, G.; URBINA, T.; VAZQUEZ DE CASTRO, E. (Org.). Mediación, Arbitraje y Resolución Extrajudicial de Conflicto en el Siglo XXI. Madrid: Reus S. A., 2010.

WERNECK VIANNA, L. et al. A judicialização da política e das relações sociais no Brasil. Rio de Janeiro: Revan, 1999.

\footnotetext{
Recebido para publicação em abril de 2014

Versão final em fevereiro de 2015

Conflito de interesses: inexistente

Suporte financeiro: Pesquisa sobre Mediação Sanitária

desenvolvida junto à Universidad de Cantabria, fruto de bolsa de

Pós-doutoramento do CNPq (Programa Ciência Sem-Fronteira)
} 